\title{
Marte Meo and Coordination Meetings (MAC): A Systemic School- Based Video Feedback Intervention-A Randomised Controlled Trial
}

\author{
Stina Balldin ${ }^{1}$ (D) Martin Bergström ${ }^{1} \cdot$ Ingegerd Wirtberg $^{2} \cdot$ Ulf $_{\text {Axberg }}^{3}$
}

Published online: 21 November 2018

(c) The Author(s) 2018

\begin{abstract}
Children displaying early disruptive behaviour problems (DBP) in school are at risk for severe long-term problems. This study evaluated and compared a systemic school-based intervention, Marte Meo and Coordination meetings (MAC) with service as usual (SAU) in a randomised controlled trial. The teachers' and parents' ratings were collected before and after intervention. Target group were children aged 3-12 years that displayed DBPs in school $(\mathrm{N}=99)$. MAC programme was more effective than SAU in reducing DBPs among school children based on teachers' reports $\left(\mathrm{d}_{\mathrm{ppc} 2} .30-.38\right)$, whereas the effect was equal according to parents' reports. It is possible to achieve changes in children's DBPs in a school setting. Advantages of MAC might be explained by a clear target for change enhancing children's development in school, but might also be explained by shortcomings in SAU, which seems to generate more services and personnel.
\end{abstract}

Keywords Disruptive behaviour problems $\cdot$ Video feedback $\cdot$ Marte Meo $\cdot$ School-based intervention $\cdot$ Systemic . Randomised controlled trial

The younger the children are when they begin to display disruptive behaviour problems (DBP), such as aggressiveness, truancy, defiance, non-compliance, impulsiveness or oppositional behaviour, the greater is the long-term risk of severe problems later in life (Franken et al., 2016; Frick, 2004; Moffitt, 2003; Patterson, DeGarmo \& Knutson, 2000; Webster-Stratton, Reid \& Beauchaine, 2011). DBP is common in childhood and is the most common reason for referrals to child psychiatric and social services (Epstein, Fonnesbeck, Potter, Rizzone \& McPheeters, 2015; Furlong et al., 2012). There is clear evidence that many lifetime psychiatric problems will first appear in childhood, which highlights the importance to intervene in early age (Costello, Egger \& Angold, 2005; Stoltz, van Londen, Dekovic, de Castro \& Prinzie, 2012). DBP poses an increased risk for the child's psychosocial development and might

Stina Balldin

stina.balldin@soch.lu.se

1 School of Social Work, Lund University, Box 23, 22100 Lund, Sweden

2 Department of Psychology, Lund University, Box 23, 22100 Lund, Sweden

3 Department of Psychology, University of Gothenburg, Box 500, 40530 Gothenburg, Sweden amplify ambient negative expectations which in turn affects the child's self-image (Patterson, Reid \& Dishion, 1992; Reid \& Eddy, 2002; Snyder, Cramer, Afrank \& Patterson, 2005). Furthermore, positive caring experiences during early school years can have long-term consequences since development occurs rapidly in interaction with the child's individual circumstances and the surrounding environment. An early experience of positive and supportive interaction as well as the experience of adversities in interactions can partially shape later experiences (Fisher, Frenkel, Noll, Berry \& Yockelson, 2016; Rutter, 2013; Rutter, Moffitt \& Caspi, 2006; Sroufe, Coffino \& Carlson, 2010).

Systematic reviews and meta-analyses on psychosocial interventions for children displaying DBPs, provides strong evidence for child-focused and behavioural interventions that includes a parent component, alone or in combination with other components (Burkey et al., 2018; Epstein et al., 2015). As an example, structured parent training programmes have been shown to be effective as well as costeffective in treating children's DBPs (Furlong et al., 2012). However, the implementations of these programmes face a number of challenges as families with children displaying DBP are often both hard to reach and hard to treat, and the attrition rates are high in both recruitment and the treatment phase. In a review by Chacko et al. (2016) at least 51\% of 
the cases-where parent training would be appropriatedropped out of treatment. Thus, there is a strong need to find additional arenas for interventions. In addition, intervention designed to support children's psychosocial development may be implemented in more than one arena (Reid \& Eddy, 2002). The generalised effects, that is from one context (e.g., home) to another (e.g., school) regarding DBPs might be limited (Borduin, Dopp \& Taylor, 2013; Fraser, Richman, Galinsky \& Day, 2009; Kaminski, Valle, Filene \& Boyle, 2008).

Based on a systemic perspective, children learn to socialize in two major arenas-family and school. These two major contexts are important at the same time as these are influenced by the surrounding environment in a broader sense (Bronfenbrenner, 1979). As virtually all children attend school (school refers to both school and preschool, in Sweden approximately $90 \%$ of children aged 1-5 attend preschool), school provides an excellent context to detect and intervene when the children are young and when children begin to display DBP (Sanchez et al., 2018; Stoltz et al., 2012; Wilson \& Lipsey, 2007). It provides an established setting where professionals from school and social services can work together to support children's developmental needs. School-based interventions have proved to be of value for children's positive adaption and social-emotional adjustment, such as positive relationships with classmates and teachers (Christensen \& Sheridan, 2001; Cox, 2005; Luthar \& Cicchetti, 2000; Mendez, Ogg, Loker \& Fefer, 2013; Reddy, Newman, De Thomas \& Chun, 2009; Reid \& Eddy, 2002; Stoltz et al., 2012). Besides, the school is defined as an environment in which both knowledge acquisition and personal development shall be promoted and supported, and where co-operation between school and family is central to the achievement to these goals (Swedish Statute Book 2010:800, 2010).

However, in the development of school-based interventions, it is important to address the collaboration between home and school (Anderson, Ringle, Ingram, Ross \& Thompson, 2017; Christensen \& Sheridan, 2001; Mendez et al., 2013; Reid \& Eddy, 2002; Sheridan \& Moorman Kim, 2015). Children's need for extra support often becomes apparent in their behaviour and interaction with others (Wirtberg, Petitt \& Axberg, 2013). Both parents and teachers have the opportunity to influence the children in their care on a day-to-day basis, for example, by promoting positive interaction using supportive dialogue (Aarts, 2008; Durlak, Weissberg, Dymnicki, Taylor \& Schellinger, 2011; Fukkink \& Tavecchio, 2010; Wirtberg et al., 2013). When a child is described as having problems, there is a risk that a problem-affirming system of communicative behaviour develops around her (Patterson et al., 1992; Sheridan \& Moorman Kim, 2015), and cooperation between family and school have proved to be critical for children's positive adaption, e.g., behaviourally manifested social competence, or success at meeting stage-salient developmental tasks, and social-emotional adjustment such as positive relationships with classmates and teachers (Luthar \& Cicchetti, 2000; Sheridan \& Moorman Kim, 2015). A positive relationship with family, peers and teachers are an important part of children's daily life and psychosocial well-being (Sameroff \& Fiese, 2000; Stewart-Brown, 2008; Stewart-Brown \& Schrader-McMillan, 2011).

Further, children who complete school and achieve adequate results stand a better chance of pro-social development throughout their life (Greenberg, Domitrovich \& Bumbarger, 2001; Hattie, 2009; Rutter, 2000). It is also important to note that interventions that provide even minor reductions of DBP are of clinical relevance for the child, her peers, and the teaching context generally as they lead to increased opportunities for learning (Hattie, 2009; Wilson \& Lipsey, 2007). In a review of school-based interventions in child mental health (Paulus, Ohmann \& Popow, 2016) it is stated that school can serve as an identifier as well as a basis for treating children that display problems related to mental health. Further, that collaboration and continuing communication between parents and teachers will help improve the child's behaviour. When implementing programmes in the school setting, the importance of integrating the programme into school goals and into the regular school activities is stressed (Paulus et al., 2016).

In this study, a school-based intervention called Marte Meo and Coordination meetings (MAC) is evaluated and compared with service as usual (SAU) in a randomised controlled trial. The target group is children (3-12 years old) that are displaying disruptive behaviour problems in school (in this case preschool and primary school). The study is an effectiveness study, conducted in a natural environment (Fraser et al., 2009).

MAC is a systemic school-based intervention that support children's development in school (Wirtberg et al., 2013) and has shown promising results in a quasi-experimental study (Axberg, Hansson, Broberg \& Wirtberg, 2006). The MAC programme consists of two core parts, (1) coordination meetings between school and family and (2) Marte Meo support in the school for the teacher. There is also one additional optional part, Marte Meo therapy in the family for the parents. A core component in Marte Meo is video feedback (VF), used to help children and adults to restore and build a supportive dialogue when communication is marked by perturbation and disturbances.

Coordination meetings reflect a systemic perspective (Petitt, 2016) based on the assumption that the education and socialisation of children is a responsibility shared between family and school. One basic principle used continually to promote the possibility of collaboration problem-solving during meetings is that a child's perceived 
and presented problem is re-contextualized (reframed) as the expression of a need for a developmental support from her network. Coordination meetings are designed to provide a structure within which collaborative problemsolving may occur - where both parents and teachers can discuss thoughts and feelings around the child's displayed DBPs and promote joint strategies (Wirtberg et al., 2013). Another principle widely used is that of the "open dialogue method" (Seikkula, Arnkil \& Eriksson, 2003). Both principles are used to support the goal of avoiding the establishment of further problem-affirming, negativefeedback cycles.

The name "Marte Meo" is derived from Latin and can be understood as "of one's own strength" (Aarts, 2008). Marte Meo was developed within the tradition of VF programmes, were parents are filmed when interacting with a child and then invited to watch and reflect on the video recording under guidance of a professional (Balldin, Fisher \& Wirtberg, 2018; Fukkink, 2008). The focus chosen for reflections will differ depending on the theoretical base of the VF programme: for example, some programmes focus more on behaviour while other focus on parental sensitivity and attachment (Balldin et al., 2018; Fukkink, 2008).

Like several other VF programmes (Balldin et al., 2018), Marte Meo may be linked to attachment theory (Bowlby, 1988) and/or social learning theory (Bandura, 1977). The fundamental idea is that children develop their psychosocial skills in interaction with supportive adults (Aarts, 2008; Bråten, 1998; S. Bråten \& Trevarthen, 2007; Øvreeide \& Hafstad, 1996). Marte Meo contains concrete and detailed information about how to intervene in daily life to stimulate positive interaction in order to support the child's development (Aarts, 2008; Wirtberg et al., 2013). The core of the Marte Meo programme is the concept of the developmentsupportive dialogue which is organised into themes (focus of attention, confirmation, turn-taking, naming, triangulating, and reciprocal startings and endings). These themes provide the basis for the analysis of the video recording and for creating the intervention that will be presented to teachers or parents (Wirtberg et al., 2013).

At the first coordination meeting, the coordinator helps the parents and teachers to define and agree upon a common goal for the intervention. The next step is to video-record approximately 5-10 min of interaction between child and teacher (and between child and parent when so agreed). The Marte Meo consultant or therapist will analyse and edit the video and then use the edited material and review and discuss it together with the teachers or parents. Focus is on helping adults to see the specific child's need of specific support and thus be able to adapt their own behaviour in a way that will promote the child's psychosocial development. The adult is then given the task of practising this in daily situations (Wirtberg et al., 2013).

\section{Aim}

The aim of the current study is to compare the MAC programme with SAU among 3-12-year-old children in school. Further, to determine if there are any generalisation effects to home. The research questions are:

1. Is there any difference between MAC and SAU regarding children's behaviour in school, (teachers' report, primary outcome)?

2. Do effects generalise from school to the home in terms of children's DBP (parents' report, secondary outcome)?

\section{Method}

A pre-post randomised controlled trial was carried out between 2009 and 2012 to examine MAC versus SAU (Fig. 1). The School of Social Work, Lund University, and four municipalities in western part of Sweden cooperated on this.

\section{Participants}

A total of 101 children from schools in four municipalities with similar sociodemographic structures were assessed for eligibility and included in the study (Fig. 2). However, two families withdrew from the study before completing the initial questionnaires, thus teachers and parents of 99 children ( 80 boys and 19 girls) participated in the study. The mean age for children was 6.6 years $(\mathrm{SD}=2.5)$. As more mothers than fathers responded at both pre- and post-test (no significant differences were found in pre-scores), primary parental informants were mainly mothers, with two fathers as exceptions. The mean age for the primary parental informants was 35.8 years $(\mathrm{SD}=6.4)$. There were no significant differences in pre-test between the intervention groups regarding sociodemographic variables, such as parent's and child's gender and age, parent's education and marital status, moving home, self-reported parental health, and benefits received from social services in the last year.

The attrition is presented in a flow chart (Fig. 2). From the 101 included children and their parents, 91 families completed the intervention and were included in the analysis (attrition was $8.1 \%$ ). There was no significant difference in

\begin{tabular}{llll}
\hline$R$ & $O$ & $X_{M A C}$ & $O$ \\
$R$ & $O$ & $X_{S A U}$ & $O$ \\
\hline
\end{tabular}

Fig. 1 Schematic diagram of randomisation design 


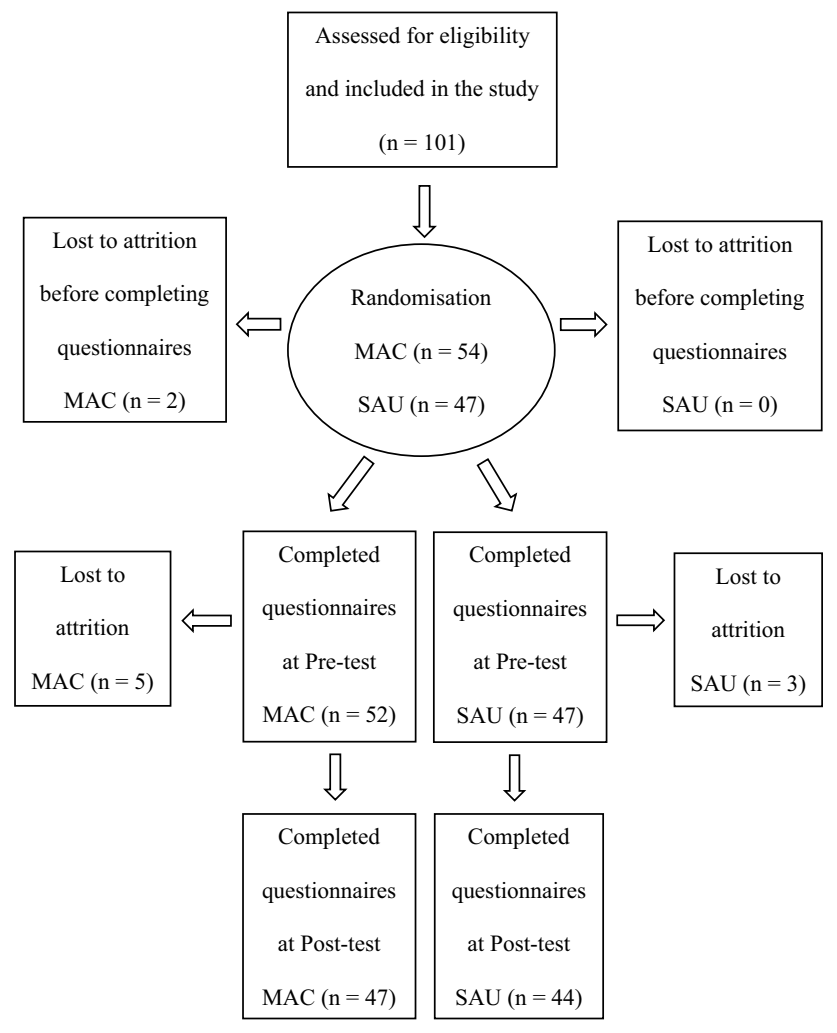

Fig. 2 Flowchart presenting the sample through the study

attrition between MAC and SAU $\left(\chi^{2}=2.95, \mathrm{p}=.09, \mathrm{df}=1\right)$. Reasons for attrition were such things as withdrawal of consent, replacing of pedagogues, or change of school or municipality.

\section{Instruments}

Two perspectives were in focus in this study: teachers' (primary outcome) and parents' (secondary outcome) ratings of the children's disruptive behaviour. Three well-knownin research instruments from ASEBA (Achenbach System of Empirically Based Assessment) were used (Achenbach $\&$ Rescorla, 2001), Teacher Report Form (TRF) and two Child Behaviour Checklist (CBCL) forms, age 1.5-5, and age 6-18. A disruptive behaviour problems scale (TRF-DBP and CBCL-DBP) was constructed to especially catch potential changes in the target behaviours of the interventions. Cronbach's alpha for the two TRF syndrome scales was from .93 to .95 in the current study. The Cronbach's' alpha for the CBCL scales in the present study was between .91 and .95 . TRF and CBCL have been translated into Swedish and normative Swedish data have been published elsewhere (Höök \& Cederblad, 2008; Larsson \& Frisk, 1999; Olsson, Hansson \& Söderlind, 2012).

The Sutter-Eyberg Student Behaviour InventoryRevised (SESBI-R) and Eyberg Child Behaviour Inventory
(ECBI) are frequently used both clinically and in research, to measure DBPs in 2-16-year-old children (Axberg, Johansson \& Broberg, 2008; Eyberg \& Pincus, 1999). They consist of two parts, the Intensity Scale (IS), which is the summed frequency of specific DBP, and the Problem Scale (PS), which reflects whether the teacher/parent perceives the specific behaviour as "a problem" or not. The IS consists of a seven-point scale ranging from $1=$ "never happens" to $7=$ "always happens", while the PS is based on dichotomous ratings on each item (1 $=$ "yes", it is a problem, or $0=$ "no", it is not a problem). The SESBI-R and ECBI have been translated into Swedish, and normative Swedish data have been published elsewhere (Bergström \& Balldin, 2017). Cronbach's alpha on the SESBI-R IS was .97 and .96 on the SESBI-R PS, the ECBI IS was .81 and .75 on the ECBI PS. Teachers and parents answered two questionnaires each, TRF and SESBI-R for teachers and CBCL and ECBI for parents. In addition, the parents answered a questionnaire regarding sociodemographic questions.

\section{Procedure}

The study was part of a governmental public health project to improve children's mental health (Wirtberg, 2014) and all preschools and schools in the four municipalities were invited to participate in the study. Children that displayed DBPs or social interaction difficulties in school were recruited. The children and their families were referred through already existing structures within the school system. The study was performed in a natural setting and it was the teacher's observations that raised concern about the child's need of support. Children who the teachers regarded as having a need of additional support were referred to the school-based mental health service. Basically, at least one of the following three criteria had to be identified in order for the child to be eligible for inclusion in the interventions:

I. Social exclusion: not being chosen by other children to participate in work or play; being actively rejected by peers and not being invited to children's parties or other events outside school

II. Behavioural problems: lack of competence when it comes to taking prosocial initiatives and responding to the communication of others and displaying conduct problems such as aggressive behaviour, being unruly, bullying, disturbing the class etc.

III. Child's own well-being: low self-confidence; seems generally unhappy as well as experiencing that others often treat her/him unfairly; poor school performance; learning difficulties; difficulties in concentration and in completing tasks 
Children already subject to treatment in social services or child psychiatry were not included in the study. Randomisation took place through the use of pre-sealed envelopes. The randomisation was blind for both the project leader and the research coordinator who did not have direct contact with the person administering the randomisation process. No stratification was used in the randomisation process. A lottery was used rather than a computer programme. Data were collected from teachers and parents at baseline, and 8 months post-baseline, by a specially trained teacher and a research assistant. All participation in the study was voluntary and informed consent was obtained from the parents. Participating families could at any time discontinue their participation in research but still complete the intervention. The teachers were not blinded to treatment. Teachers participating in the study may have influenced the way their colleagues worked with the other children. As the study was carried out in an everyday school environment it was not possible to prevent or minimize a certain 'spill-over' effect. However, the core component in MAC, namely VF, was not allowed in SAU. The study was reviewed and approved by the Central Ethical Review Board in Sweden (ref.nr. 2009/323).

\section{Marte Meo and Coordination Meetings (MAC)}

Personnel were recruited from ordinary staff; MAC coordinators from school or social services, Marte Meo consultants from school. Marte Meo therapists were provided by social services. Parent(s), teacher(s) and Marte Meo consultants/ therapists met at coordination meetings on school premises at least three times with a minimum of two weeks apart. To ensure programme fidelity, one person monitored MAC implementation, Marte Meo consultants met with external Marte Meo consultants and a Licensed Marte Meo Supervisor, and Marte Meo therapists received similar supervision. All Marte Meo supervision took place with filmed interaction and filmed reviews, and programme adherence schedules were self-completed and added to the case files. The coordinators had regular supervision from the coordination meeting originators and also completed self-administered adherence schedules after each coordination meeting.

Through cooperation between school and social services, the MAC intervention was added to whatever regular support the children had previously been offered in the school. A MAC team was formed in each of the participating municipalities. It consisted of teachers with additional training in working with children with special needs and who had been trained as Marte Meo consultants and coordinators who were recruited from social services. In addition, the social services would provide Marte Meo therapy in the home when required by the family. This would be provided by social workers with additional training as Marte Meo therapists.
The MAC intervention was adapted to the specific child's need of support and number of sessions was not predetermined. However, no intervention lasted longer than 6 months. The coordination meetings took place every second week and averaged 5 in number (range 2-12). Marte Meo intervention in school (including filming and reviewing) averaged 5 in number (range 2-12). Marte Meo therapy in the family (including filming and reviewing) averaged 3 in number (range 1-7). The number of films for each intervention shown at the coordination meetings averaged 1 (range $0-5)$.

\section{Service as Usual (SAU)}

To get an idea of the support this group received, teachers $(n=33)$ and parents $(n=33)$ were asked about this at posttest. The support varied, from more extensive support to nothing and resembled traditional support offered in school when a child displays DBP. Support for teachers consisted of supervision $(n=11)$ or consultation $(n=20)$, support for the child was classroom observation $(n=21)$ or assessment performed by psychologist or social service $(n=5)$, while family support consisted of consultation $(n=3)$, family treatment $(n=2)$, assessment by social services $(n=1)$ or a psychologist in primary care $(n=1)$. Sometimes there was a combination of efforts. SAU generated more services than MAC did.

\section{Data Analysis}

First, we dealt with lack of data. Following instructions from the manuals of the different measures, the scales were not used if there were more than the stipulated items missing on the SESBI-R/ECBI, CBCL, and TRF. Less than one percent were missing on single items on all measures (range $0.1-0.6 \%$ ). Missing values were replaced by the item mean of the individual. If the scale had a subscale the item mean value of the subscale was used. Intention-To-Treat (ITT), with a Last Observation Carried Forward (LOCF) approach, was used to avoid overestimation of the improvement rates (Overall, Tonidandel \& Starbuck, 2009). That is, in the cases where the families dropped out their results were counted as unchanged. Second, we dealt with outliers. The data were examined and a few outliers were found in addition to a nonnormal distribution. To reduce the impact of outliers and non-normality, a square root transformation of the data was performed (Field, 2005). However, raw data are presented in the Descriptives table (Table 1).

The data were then handled in two ways. First, we explored group level. To examine the randomisation, baseline differences between MAC and SAU were analysed using $\chi^{2}$-tests or $t$-tests. In-group differences between preand post-ratings were calculated using pairwise $t$-test. To 
Table 1 Descriptives: teachers' and primary parental informants' pre-ratings, raw points

\begin{tabular}{|c|c|c|c|c|c|c|c|}
\hline \multirow[t]{2}{*}{ Measure } & \multicolumn{3}{|c|}{ MAC } & \multicolumn{3}{|c|}{ SAU } & \multirow[t]{2}{*}{$p$} \\
\hline & $\mathrm{N}$ & M & SD & $\mathrm{N}$ & M & SD & \\
\hline \multicolumn{8}{|c|}{ Teachers' pre-ratings } \\
\hline TRF-DBP & 47 & 35.19 & 19.11 & 47 & 32.37 & 19.54 & .47 \\
\hline TRF-TOT & 52 & 55.72 & 24.06 & 47 & 53.25 & 23.40 & .61 \\
\hline SESBI-R IS & 52 & 152.38 & 40.96 & 47 & 145.14 & 48.38 & .42 \\
\hline SESBI-R PS & 50 & 17.25 & 9.79 & 45 & 16.60 & 10.62 & .76 \\
\hline \multicolumn{8}{|c|}{ Primary parental informants' pre-ratings } \\
\hline CBY-DBP & 18 & 17.78 & 9.89 & 22 & 20.56 & 11.43 & .42 \\
\hline CBY-TOT & 18 & 28.17 & 16.61 & 22 & 31.71 & 22.36 & .58 \\
\hline CBO-DBP & 34 & 30.30 & 18.12 & 24 & 20.26 & 13.17 & .02 \\
\hline СВO ТОТ & 34 & 49.36 & 30.67 & 23 & 33.47 & 18.68 & .02 \\
\hline ECBI IS & 50 & 114.72 & 35.88 & 47 & 103.04 & 34.17 & .10 \\
\hline ECBI PS & 46 & 10.29 & 8.42 & 45 & 7.29 & 7.85 & .09 \\
\hline
\end{tabular}

$T R F$ teacher report form, $D B P$ Disruptive Behavior Problem Scale, TOT total problem score, SESBI-R Sutter-Eyberg behavior inventory-revised, $I S$ Intensity Scale, $P S$ problem Scale, $C B Y$ CBCL for younger children, $C B O$ CBCL for older children, ECBI Eyberg Child Behavior Inventory calculate effect size and $95 \%$ confidence intervals of the effect size, we used the Exploratory Software for Confidence Intervals (ESCI) (Cumming \& Calin-Jageman, 2017). The Excel-based software used for calculations was downloaded from http://www.thenewstatistics.com. A value of .20 is considered a small effect, .50 medium and .80 large (Lakens, 2013). Potential differences between preschoolers and schoolchildren were also controlled for using independent $t$-test. To test if there were any statistically significant differences in outcomes an analysis of covariance (ANCOVA) was performed, with group as a fixed factor, post-scores as dependent variable, and pre-scores as covariate controlling for age and gender. Additionally, the pretest-posttest-control effect size $\left(d_{p p c 2}\right)$ of difference between groups was calculated using a method proposed by Morris (2008) in which effect size is calculated on the mean pre-post change in the treatment group minus the mean pre-post change in the control group, divided by the pooled pre-test standard deviation. The ESCI was also used when calculating the $95 \%$ confidence interval of these effect sizes. In addition, we calculated the overall effect size and $95 \%$ confidence interval for the primary and secondary outcome variables respectively, using the meta-analysis tool of the ESCI.

Second, a person-centred approach to calculate reliable change (Reliable Change Index, RCI) proposed by Jacobson and Truax (1991) was used to assess clinical significance. RCI has proven to be appropriate when reporting change at the individual level (Wolpert et al., 2015). Following recommendations from Lambert and Ogles (2009) the internal consistency was used in the calculations instead of test-retest reliability. Furthermore, the $\alpha$-level was set to .01 for a statistically reliable change in line with recommendations from Burgess, Pirkis, and Coombs (2009). In a first step the change of each subject was calculated by dividing the pre-post-difference by the standard error (SE) of the difference score to ensure that the individual change was larger than could be attributed to chance or measurement error. In the next step the outcome was compared to normative data in which clinical cut-off levels were established.

Thus, it was possible to determine the proportion of children who had recovered (significantly improved from over to under cut-off level), improved (but not passed the cutoff), not changed, worsened or deteriorated (worsened and gone from below to over cut off) (Tables 3, 5). Still, attrition means the sample size differed in the various analyses.

The clinical cut-off level corresponded to the 90th percentile as recommended by the Swedish standards for the various measuring instruments (Bergström \& Balldin, 2017; Höök \& Cederblad, 2008; Larsson \& Frisk, 1999; Olsson et al., 2012). Since we had access to the original database for the TRF norms (Olsson et al., 2012), norms for TRF DBP scale were included.

The statistical analyses were performed in SPSS version 20.0 .

\section{Result}

Randomisation ensured that the two groups were equalised at baseline. Descriptives of teachers' and primary parental informant's pre-ratings is presented in Table 1 .

The predominant result showed that randomisation mainly equalised the primary outcome variables (Table 1). However, two outcome variables significantly differed, CBO Total Scale and CBO DBP scale. This was managed by performing an ANCOVA, with pre-ratings as covariate. We 
also controlled for age at pre-test, using TRF, ECBI, and SESBI-R, which showed no significant differences between preschoolers (age 3-6) and schoolchildren (age 7-13).

Results regarding children displaying positive behaviour change were primarily expected at school. Therefore, we first analysed the group effects (MAC versus SAU) based on teachers' ratings (Table 2).

There were statistically significant reductions in teachers' ratings in all the primary outcome variables for the MAC group. Effect sizes in the MAC group were in the small to medium range, the SESBI-R Problem Scale was clearly below medium. The only statistically significant reduction for the SAU group was found on the SESBI-R Intensity Scale where the effect size was in the small range. The ANCOVA revealed that there were statistically significant difference on the SESBI-R IS $(\mathrm{F}(1,85)=4.404, \mathrm{p}=.04$, $\mathrm{d}_{\mathrm{ppc} 2}=.30[\mathrm{CI}-.12$ to .72$\left.]\right)$, the constructed TRF DBP scale $\left(\mathrm{F}(1,86)=5.546, \mathrm{p}=.02, \mathrm{~d}_{\mathrm{ppc} 2}=.36[\mathrm{CI}-.06\right.$ to .77$\left.]\right)$ and on the TRF Total Scale $\left(\mathrm{F}(1,86)=4.369, \mathrm{p}=.04, \mathrm{~d}_{\mathrm{ppc} 2}\right.$ $=.38$ [CI -0.04 to .79$]$ ) in favour of MAC. However, there was no statistically significant difference on the SESBI-R PS $\left(\mathrm{F}(1,80)=2.823, \mathrm{p}=.24, \mathrm{~d}_{\mathrm{ppc} 2}=.18[-.25\right.$ to .81$\left.]\right)$. When all the effect sizes of the primary outcome variables were used in a meta-analysis the effect size between the groups was .30 [.10-.51] in favour of MAC. The analysis was replicated using ITT values leading to the same result. The corresponding results on the SESBI-R IS was $(\mathrm{F}(1,94)=3.885$, $\mathrm{p}=.05, \mathrm{~d}_{\mathrm{ppc} 2}=.27[\mathrm{CI}-.13$ to .67$\left.]\right)$, on the constructed TRF DBP scale $\left(\mathrm{F}(1,94)=5.678, \mathrm{p}=.02, \mathrm{~d}_{\mathrm{ppc} 2}=.33[\mathrm{CI}-.07\right.$ to .73]), on the TRF Total Scale $(\mathrm{F}(1,94)=4.258, \mathrm{p}=.04$, $\mathrm{d}_{\mathrm{ppc} 2}=.39[\mathrm{CI}-.01$ to .79$\left.]\right)$ and finally on the SESBI-R PS $\left(\mathrm{F}(1,94)=.803, \mathrm{p}=.37, \mathrm{~d}_{\mathrm{ppc} 2}=.17\right.$ [CI -.23 to .57$\left.]\right)$. The meta-analysis of the ITT results revealed an effect size of .29 [CI .09-48] in favour of MAC. In the ANCOVA analyses we controlled for age, showing no significant contribution to the outcomes. Further, we calculated reported change (TRF, ECBI, and SESBI-R) from pre-test to post-test, which showed no significant differences in mean change between preschooler and schoolchildren.

The teachers' and the parent's reports at pre-test showed that between $25 \%$ and $67 \%$ of the children displayed clinical problems (TRF Total, 36\%; TRF DBP, 38\%; SESBI-R IS, 67\%; SESBI-R PS, 35\%; CBY, 25\%; CBO, $51 \%$; ECBI IS, $27 \%$; ECBI PS, $27 \%$ ). There were equally many children displaying clinical problems regardless of group $\left(\mathrm{x}^{2}\right.$-test, non-significance).

The RCI analysis revealed (Table 3) that most of the outcome variables showed significant changes in any direction,
Table 2 Square-root transformed teachers' ratings of children before and after intervention
Table 3 Proportion of reliable clinical change (RCI) according to teachers' ratings in \%

\begin{tabular}{|c|c|c|c|c|c|c|c|}
\hline \multirow[t]{2}{*}{ Measure (group) } & \multirow[t]{2}{*}{$\mathrm{N}$} & \multicolumn{2}{|l|}{ Pre } & \multicolumn{2}{|l|}{ Post } & \multirow[t]{2}{*}{$p$} & \multirow[t]{2}{*}{$\mathrm{d}(95 \% \mathrm{CI})$} \\
\hline & & M & SD & M & SD & & \\
\hline TRF-DBP (MAC) & 47 & 5.63 & 1.80 & 4.75 & 2.15 & .00 & $.44(.20-.68)$ \\
\hline TRF-DBP (SAU) & 44 & 5.34 & 1.96 & 5.15 & 2.06 & .31 & $.10(-.09$ to .29$)$ \\
\hline TRF-TOT (MAC) & 47 & 7.20 & 1.66 & 6.24 & 2.23 & .00 & $.49(.22-.76)$ \\
\hline TRF-TOT (SAU) & 44 & 7.08 & 1.75 & 6.77 & 1.99 & .15 & $.17(-.06$ to .39$)$ \\
\hline SESBI-R IS (MAC) & 46 & 12.16 & 1.84 & 11.19 & 2.27 & .00 & $.47(.23-.71)$ \\
\hline SESBI-R IS (SAU) & 44 & 11.80 & 2.18 & 11.45 & 2.33 & .04 & $.16(.10-.31)$ \\
\hline SESBI-R PS (MAC) & 43 & 3.79 & 1.57 & 3.21 & 1.87 & .02 & $.34(.25-.42)$ \\
\hline SESBI-R PS (SAU) & 42 & 3.65 & 1.81 & 3.38 & 1.89 & .26 & $.15(-.11$ to .39$)$ \\
\hline
\end{tabular}

$T R F$ teacher report form, $D B P$ disruptive behavior problem scale, TOT total problem score, SESBI-R Sutter-Eyberg behavior inventory-revised, $I S$ intensity scale, $P S$ problem scale

\begin{tabular}{|c|c|c|c|c|c|c|}
\hline \multirow[t]{2}{*}{ Measure } & \multirow[t]{2}{*}{ Group } & \multicolumn{2}{|c|}{ Sign. positive change } & \multirow[t]{2}{*}{ No change } & \multicolumn{2}{|c|}{ Sign. negative change } \\
\hline & & Recovered & Improved & & Worsened & Deteriorated \\
\hline \multirow[t]{2}{*}{ TRF-DBP } & MAC & 19.1 & 25.5 & 42.6 & 10.6 & 2.1 \\
\hline & SAU & 4.5 & 20.5 & 61.4 & 11.4 & 2.3 \\
\hline \multirow[t]{2}{*}{ TRF-TOT } & MAC & 19.1 & 38.3 & 25.5 & 10.6 & 6.4 \\
\hline & SAU & 13.6 & 25.0 & 40.9 & 15.9 & 4.5 \\
\hline \multirow[t]{2}{*}{ SESBI-R IS } & MAC & 17.4 & 37.0 & 32.6 & 13.0 & 0.0 \\
\hline & SAU & 4.5 & 31.8 & 42.2 & 18.2 & 2.3 \\
\hline \multirow[t]{2}{*}{ SESBI-R PS } & MAC & 15.9 & 25.0 & 36.4 & 13.6 & 9.1 \\
\hline & SAU & 14.0 & 18.6 & 46.5 & 18.6 & 2.3 \\
\hline
\end{tabular}

$T R F$ teacher report form, $D B P$ Disruptive Behavior Problem Scale, SESBI- $R$ Sutter-Eyberg behavior inventory-revised, $I S$ intensity scale, $P S$ problem scale 
except the TRF DBP scale in the SAU group, where more than half of the children $(61 \%)$ were unchanged. About half of the children in the MAC group displayed a significant positive change from the teachers' reports (from 41 to $57 \%$ ). In the SAU group, less positive change was reported (from 25 to $39 \%$ ). In the MAC group from 16 to $20 \%$ of the children had recovered, while between 0 and $9 \%$ had deteriorated. The corresponding numbers for the SAU group show that from 5 to $14 \%$ had recovered, and between 2 and 5\% had deteriorated. Undertaking group wise comparison, three of four outcome measures showed significant differences between the intervention groups in favour of MAC (TRF DBP: $\chi^{2}=8.7, \mathrm{df}=2, \mathrm{p}=.01$; TRF total scale: $\chi^{2}=7.6$, $\mathrm{df}=2, \mathrm{p}=.03$; SESBI-R IS: $\chi^{2}=6.4, \mathrm{df}=2, \mathrm{p}=.04$ ).

Results based on the primary parental informants' ratings (Table 4) showed that in the MAC group, there were significant differences in four out of six secondary outcome variables, while only in one out of six in the SAU group. However, only one outcome variable in both groups showed medium effect.
The ITT-analysis was in line with results from the completed analysis. Since the ANCOVA revealed that there was no statistically significant difference between MAC and SAU, analyses are not presented. The RCI analysis (Table 5) revealed that most of the secondary outcome showed no change in any direction in more than half the children (range from 56 to 77\%). The exception was CBO Total Scale in the SAU group, where most of the children showed a significant positive change (47\%).

More children displayed a positive significant change than a significant negative change in both groups. When we did group wise comparison, none of the measures showed significant differences between MAC and SAU.

\section{Discussion}

The school provides a context in which children with difficulties can be both detected and helped. This study revealed that the MAC programme is preferable to SAU in terms of
Table 4 Square-root transformed parents' ratings of children before and after intervention
Table 5 Proportion of reliable clinical change (RCI) according to primary parental informants' ratings in \%

\begin{tabular}{|c|c|c|c|c|c|c|c|}
\hline \multirow{2}{*}{ Measure (group) } & \multirow[t]{2}{*}{$\mathrm{N}$} & \multicolumn{2}{|l|}{ Pre } & \multicolumn{2}{|l|}{ Post } & \multirow[t]{2}{*}{$p$} & \multirow{2}{*}{$\mathrm{d}(95 \% \mathrm{CI})$} \\
\hline & & M & SD & M & SD & & \\
\hline CBY-DBP (MAC) & 17 & 3.99 & 1.43 & 3.57 & 1.41 & .08 & $.30(-.03$ to .62$)$ \\
\hline CBY-DBP (SAU) & 21 & 4.44 & 1.35 & 3.91 & 1.00 & .04 & $.45(.02-.87)$ \\
\hline CBY-TOT (MAC) & 17 & 5.09 & 1.70 & 4.39 & 1.74 & .03 & $.41(.04-.77)$ \\
\hline CBY-TOT (SAU) & 21 & 5.43 & 1.93 & 4.86 & 1.72 & .11 & $.30(-.07$ to .69$)$ \\
\hline CBO-DBP (MAC) & 25 & 4.95 & 1.30 & 4.45 & 1.62 & .07 & $.34(-.02$ to .71$)$ \\
\hline CBO-DBP (SAU) & 23 & 4.12 & 1.80 & 3.73 & 1.91 & .01 & $.21(.06-.37)$ \\
\hline CBO-TOT (MAC) & 25 & 6.32 & 1.81 & 5.81 & 2.05 & .12 & $.27(-.07$ to .59$)$ \\
\hline CBO-TOT (SAU) & 19 & 5.42 & 2.08 & 4.91 & 2.24 & .03 & $.24(.03-.44)$ \\
\hline ECBI IS (MAC) & 44 & 10.52 & 1.57 & 10.05 & 1.61 & .00 & $.30(.10-.49)$ \\
\hline ECBI IS (SAU) & 44 & 9.93 & 1.67 & 9.63 & 1.64 & .09 & $.18(-.03$ to .39$)$ \\
\hline ECBI PS (MAC) & 41 & 2.78 & 1.43 & 2.24 & 1.74 & .01 & $.34(.08-.60)$ \\
\hline ECBI PS (SAU) & 42 & 2.24 & 1.59 & 2.05 & 1.65 & .34 & $.12(-.12$ to .35$)$ \\
\hline
\end{tabular}

$C B Y$ CBCL for younger children, $C B O$ CBCL for older children, $D B P$ Disruptive Behavior Problem Scale, $T O T$ total problem score, ECBI Eyberg Child Behavior Inventory, IS intensity scale, $P S$ problem scale

\begin{tabular}{|c|c|c|c|c|c|c|}
\hline \multirow[t]{2}{*}{ Measure } & \multirow[t]{2}{*}{ Group } & \multicolumn{2}{|c|}{ Sign. positive change } & \multirow[t]{2}{*}{ No change } & \multicolumn{2}{|c|}{ Sign. negative change } \\
\hline & & Recovered & Improved & & Worsened & Deteriorated \\
\hline \multirow[t]{2}{*}{ CBY-TOT } & MAC & 11.8 & 11.8 & 76.5 & 0.0 & 0.0 \\
\hline & SAU & 14.3 & 9.5 & 66.7 & 4.8 & 4.8 \\
\hline \multirow[t]{2}{*}{ СВО-TOT } & MAC & 16.0 & 12.0 & 56.0 & 12.0 & 4.0 \\
\hline & SAU & 10.5 & 36.8 & 36.8 & 15.8 & 0.0 \\
\hline \multirow[t]{2}{*}{ ECBI IS } & MAC & 4.0 & 20.0 & 72.0 & 2.0 & 2.0 \\
\hline & SAU & 6.5 & 13.0 & 67.4 & 8.7 & 4.3 \\
\hline \multirow[t]{2}{*}{ ECBI PS } & MAC & 14.3 & 4.1 & 73.5 & 0.0 & 8.2 \\
\hline & SAU & 11.6 & 7.0 & 72.1 & 4.7 & 4.7 \\
\hline
\end{tabular}

$C B Y$ CBCL for younger children, $C B O \mathrm{CBCL}$ for older children, ECBI Eyberg Child Behavior Inventory, $I S$ intensity scale, $P S$ problem scale 
reducing DBP based on teachers' reports. Interventions in school contexts sometimes hold expectations of generalised effects, however MAC and SAU were equally effective according to the parents.

The overall results are not surprising since it is reasonable to expect positive changes in school when school-based interventions are performed. Those best suited to validate an impact effect are those directly affected by the problem. In our study, the teachers had detected children who showed increasing interaction difficulties and/or behaviour problems (DBPs). Short-term effects might be valuable for those directly involved because of reduction in the children's displayed DBPs, or at least a change in teachers' experience of the child's DBPs. This in turn is expected to have a moderating effect on the interaction between teacher and child, in which the child is confirmed in a more positive way, with emphasis on supporting pro-social behaviour. This can also have a positive effect on interaction with peers. A short-term effect is the teachers' changed way of describing the children, e.g. less problem oriented, which might also influence on the parents. When the teachers-and the child-experience change, this might give hope for a continued change process. Given the enhanced risk of life-term difficulties for children displaying DBPs, the effects can indicate a turning point for those children in the MAC group.

When the parents reported the child's displayed DBPs, neither MAC nor SAU were preferable from the parent's reports. This means that the results were not generalised from one context (school) to another (home). There could be different reasons for this. First, possibly effects from DBP interventions might not be expected in another context (Kaminski et al., 2008; Scott, 2002; Webster-Stratton $\&$ Taylor, 2001). If the effects were to be expected in more than one context, the intervention had to take place in more than one context. Secondly, it might take time to generalise effects from one context to another. The short-term effects observed in the daily school context might not be expected to be observed in the family context. Only less than onefifth of the children in the MAC group received Marte Meo therapy in the family and in the SAU group family interventions were even fewer. Thus, it would be expected that the documented change took place in the school setting.

The MAC programme contains a clear and concrete strategy involving teachers and parents using VF to identify opportunities for change and there is a clear focus on the defined target for change. SAU appeared to be focused more on problem management and required more resources in general both in terms of services and personnel. There was a clear focus in MAC on change in the child's behaviour, while the focus in SAU might have been more problem oriented. This could be one of the major reasons for these results-only paying attention to the problem seems insufficient (Borduin et al., 2013;
Stewart-Brown \& Schrader-McMillan, 2011; Wilson \& Lipsey, 2007). SAU might have no compensatory effect in reducing children's DBPs. When the outcomes reported by the teachers and parents were put together, we can present one mean effect size result for MAC teachers and parents, and one for SAU teachers and parents. The mean effect size (d) of the four and six outcomes respectively were in range small to medium for MAC teachers, and small for parents in both MAC and SAU. However, the same mean effect size reported by the teachers in SAU indicated no effect (less than .20) and show that a minority of the children had a negative change (14-22\%). This indicates on an individual level that the majority still did not have a negative change. The merged effect sizes of the primary outcome measures in MAC and SAU showed that the effect difference between the groups was .30 in favour of MAC.

The results of the RCI for the MAC group (teachers' ratings) are encouraging since this was a non-clinical setting where not all children displayed DBPs on a clinical level. Warren, Nelson, Mondragon, Baldwin, and Burlingame (2010) found in a meta-analytic study of children (age 4-17) in outpatient community mental services that less than $50 \%$ of the children displayed a statistically significant improvement and $21 \%$ showed a statistically significant impairment after treatment.

The results in this study are promising compared with other studies. A meta-analysis concerning school-based interventions for aggressive and disruptive behaviour (Wilson \& Lipsey, 2007) showed that universal and targeted programmes for selected/indicated children were the most common and most effective approaches (effect sizes of .21 and .29). Additionally, Wilson and Lipsey (2007) stated that there is little evidence regarding the actual effectiveness in everyday real-world practice. In another study (Stoltz et al., 2012), which included two meta-analyses of school-based interventions, the mean effect size was .30 in reducing externalizing behaviour problems. Furthermore, Stoltz et al. (2012) found that age appeared to be a significant moderator in contrast to the current study where no difference was found.

It is suggested that VF improves the interaction skills of early childhood teachers (for example socio-emotional support, sensitivity and verbal responses) although there is a need to identify core factors correlating with the effectiveness of VF (Fukkink \& Tavecchio, 2010; Fukkink, Trienekens \& Kramer, 2011). A meta-analysis regarding VF in education and training demonstrated the effect size .40 on the interaction skills of professionals in a wide range of professions (Fukkink et al., 2011).

To conclude, the results of this study, performed in a natural setting, are promising in the short-run and in line with previous research. However, even if short-term effects are valuable it is desirable that impact is sustainable over time 
as there is a risk of long-term consequences when children display DBPs.

\section{Limitations}

A study performed within the natural setting meant that the researchers' involvement had to be minimised, or else this might have influenced the daily practice as well as the teachers' and parents' ratings. However, this led to some shortcomings in routines, such as form distribution. Another challenge was the possible 'spill-over' effect. For example, MAC teachers handling situations in new ways might have affected their SAU colleagues, which was not controlled for. Another limitation was that we did not register the specific schools and therefore cannot report the number of schools involved.

Due to the broad range of children included in the study, it was difficult to know how many children could have questionable eligibility. However, the results showed that in accordance with the teachers, many children had clinical levels of problems. One limitation of self-declared reports is that the respondents can be influenced by the desire to provide socially desirable answers. A different way of measuring the effects could be to register changes in disciplinary actions or letters to parents. However, such actions or letters are not systematically widespread or documented in Swedish schools. To get a more complete picture of the effects of interventions like MAC, it might be preferable to also use other outcome measures in future studies, e.g. examining the parents' wellbeing or the children's experiences of themselves interacting with others.

\section{Conclusions}

The MAC programme is effective and a preferable intervention compared to SAU when reducing children's DBPs in school. Thus, this study shows that it is possible to achieve changes in children's DBPs in only eight months. Since even changes with small effect sizes have proved to have an impact in a school context (Wilson \& Lipsey, 2007), we suggest that these results are valuable. A decrease in DBP for almost half of the children in the MAC group should make a noticeable, positive impact on the daily challenges, as well as on the child's network, such as peers, teachers and family members (Wilson \& Lipsey, 2007). The effects in MAC might be explained by the shortcomings in SAU effectiveness. RCI showed some side-effects since some children displayed increased DBPs. The MAC programme, focusing on relationships, interaction and behaviour provides a structured way to bring teachers and parents together when concerns for a child's development and learning in school derives. MAC comprises of a clear target for change and provides teachers and parents concrete and detailed information about intervening in daily life to support the child's specific needs. As MAC is a school-based intervention performed in already existing structures in school, this should facilitate the implementation.

Acknowledgements This study was granted by the Swedish National Board of Health and Welfare (Socialstyrelsen) and the Swedish National Institute of Public Health (Statens Folkhälsoinstitut, HFA 2008/211). We would like to thank the research coordinators Pia Svensson and Gun-Britt Sjögren, and the teachers and parents who contributed to this study. Parts of the research group (U.A and I.W) developed the MAC programme.

\section{Compliance with Ethical Standards}

Ethical Approval The Central Ethical Review Board in Lund, Sweden, ethically approved the study (ref.nr. 2009/323).

Open Access This article is distributed under the terms of the Creative Commons Attribution 4.0 International License (http://creativeco mmons.org/licenses/by/4.0/), which permits unrestricted use, distribution, and reproduction in any medium, provided you give appropriate credit to the original author(s) and the source, provide a link to the Creative Commons license, and indicate if changes were made.

\section{References}

Aarts, M. (2008). Marte Meo basic manual. Revised (2nd edition.). Eindhoven: Aarts Production.

Achenbach, T. M., \& Rescorla, L. A. (2001). Manual for the ASEBA school-age forms and profiles. Burlington: University of Vermont Research Center for Children, Youth and Families.

Anderson, L., Ringle, J. L., Ingram, S. D., Ross, J. R., \& Thompson, R. W. (2017). Care coordination services: A description of an alternative service model for at-risk families. Journal of Evidence-Informed Social Work, 14, 217-228. https://doi. org/10.1080/23761407.2017.1306731.

Axberg, U., Hansson, K., Broberg, A. G., \& Wirtberg, I. (2006). The development of a systemic school-based intervention: Marte Meo and coordination meetings. Family Process. https://doi.org/10.11 11/j.1545-5300.2006.00177.x.

Axberg, U., Johansson, H. J., \& Broberg, A. G. (2008). Parents' description of conduct problems in their children-a test of the Eyberg child behavior inventory (ECBI) in a Swedish sample aged 3-10. Scandinavian Journal of Psychology, 49, 497-505. https:// doi.org/10.1111/j.1467-9450.2008.00670.x.

Balldin, S., Fisher, P. A., \& Wirtberg, I. (2018). Video feedback intervention with children: A systematic review. Research on Social Work Practice, 28, 682-695. https://doi.org/10.1177/1049731516 671809.

Bandura, A. (1977). Social learning theory. Englewood Cliffs: Prentice Hall.

Bergström, M., \& Balldin, S. (2017). Swedish standardization of two assessment tools for teachers. Connor's Teacher Rating Scale (CTRS) och Sutter-Eyberg Student Behavior Inventory-Revised (SESBI-R). Lund: School of Social Work, Lund University.

Borduin, C. M., Dopp, A. R., \& Taylor, E. K. (2013). Evidence-based interventions for serious and violent juvenile offenders. In A. C. Leam, L. Dixon \& T. A. Gannon (Eds.), What works in offender 
rehabilitation: An evidence-based approach to assessment and treatment (pp. 192-210). Mississauga: Wiley.

Bowlby, J. (1988). A secure base: Clinical applications of attachment theory. London: Routledge.

Bråten, I. (1998). Vygotskij och pedagogiken. [Vygotskij and the pedagogy]. Lund: Studentlitteratur.

Bråten, S., \& Trevarthen, C. (2007). Prologue: From infant intersubjectivity and participant movements to simulation and conversation in cultural common sense. In S. Bråten (Ed.), On being moved: From mirror neurons to empathy (pp. 21-34). Amsterdam: John Benjamins.

Bronfenbrenner, U. (1979). The ecology of human development: Experiments by nature and design. Cambridge: Harvard University Press.

Burgess, P., Pirkis, J., \& Coombs, T. (2009). Modelling candidate effectiveness indicators for mental health services. Australian \& New Zealand Journal of Psychiatry, 43, 531-538. https://doi. org/10.1080/00048670902873656.

Burkey, M. D., Hosein, M., Morton, I., Purgato, M., Adi, A., Kurzrok, M., ... Tol, W. A. (2018). Psychosocial interventions for disruptive behaviour problems in children in low- and middle-income countries: A systematic review and meta-analysis. Journal of Child Psychology and Psychiatry. https://doi. org/10.1111/jcpp. 12894.

Chacko, A., Chimklis, A., Chan, E., Lee, D., Pulgarin, B., Jensen, S. A., ... Cornwell, M. (2016). Engagement in behavioral parent training: Review of the literature and implications for practice. Clinical Child and Family Psychology Review, 19, 204-215.

Christensen, S. L., \& Sheridan, S. M. (2001). Schools and families: Creating essential connections for learning. New York: Guilford Press.

Costello, E. J., Egger, H., \& Angold, A. (2005). 10-year research update review: The epidemiology of child and adolescent psychiatric disorders: I. Methods and public health burden. Journal of the American Academy of Child and Adolescent Psychiatry, 44, 972-986. https://doi.org/10.1097/01.chi.0000172552.41596 $.6 \mathrm{f}$.

Cox, D. D. (2005). Evidence-based interventions using home-school collaboration. School Psychology Quarterly, 20, 473-497. https ://doi.org/10.1521/scpq.2005.20.4.473.

Cumming, G., \& Calin-Jageman, R. (2017). Introduction to the new statistics: Estimation, open science, and beyond. New York: Routledge.

Durlak, J. A., Weissberg, R. P., Dymnicki, A. B., Taylor, R. D., \& Schellinger, K. B. (2011). The impact of enhancing students' social and emotional learning: A meta-analysis of school-based universal interventions. Child Development, 82, 405-432.

Epstein, R. A., Fonnesbeck, C., Potter, S., Rizzone, K. H., \& McPheeters, M. (2015). Psychosocial interventions for child disruptive behaviors: A meta-analysis. Pediatrics, 136, 947-960. https://doi.org/10.1542/peds.2015-2577.

Eyberg, S., \& Pincus, D. (1999). Eyberg child behavior inventory $($ ECBI) \& Sutter-Eyberg student behavior inventory-revised (SESBI-R): Professional manual. Odessa: Psychological Assessment Resources.

Field, A. (2005). Discovering statistics using SPSS: (and sex, drugs and rock'n'roll). London: SAGE.

Fisher, P. A., Frenkel, T. I., Noll, L. K., Berry, M., \& Yockelson, M. (2016). Promoting healthy child development via a two-generation translational neuroscience framework: The filming interactions to nurture development video coaching program. Child Development Perspectives, 10, 251-256. https://doi.org/10.1111/cdep.12195.

Franken, A., Harakeh, Z., Vollebergh, W. A. M., Moffitt, T. E., Steglich, C. E. G., \& Dijkstra, J. K. (2016). The role of self-control and early adolescents' friendships in the development of externalizing behavior: The snare study. Journal of Youth and Adolescence, 45, 1800-1811. https://doi.org/10.1007/s10964-015-0287-z.

Fraser, M. W., Richman, J. M., Galinsky, M. J., \& Day, S. H. (2009). Intervention research. Developing social programs. New York: Oxford University Press.

Frick, P. J. (2004). Developmental pathways to conduct disorder: Implications for serving youth who show severe aggressive and antisocial behavior. Psychology in the Schools, 41, 823-834. https:// doi.org/10.1002/pits.20039.

Fukkink, R. G. (2008). Video feedback in widescreen: A meta-analysis of family programs. Clinical Psychology Review, 28, 904-916. https://doi.org/10.1016/j.cpr.2008.01.003.

Fukkink, R. G., \& Tavecchio, L. W. C. (2010). Effects of video interaction guidance on early childhood teachers. Teaching and Teacher Education: An International Journal of Research and Studies, 26, 1652-1659.

Fukkink, R. G., Trienekens, N., \& Kramer, L. J. C. (2011). Video feedback in education and training: Putting learning in the picture. Educational Psychology Review, 23, 45-63. https://doi. org/10.1007/s10648-010-9144-5.

Furlong, M., McGilloway, S., Bywater, T., Hutchings, J., Smith, S. M., \& Donnelly, M. (2012). Behavioural and cognitive-behavioural group-based parenting programmes for early-onset conduct problems in children aged 3 to 12 years. Cochrane Database of Systematic Reviews. Retrieved from http://www.mrw.interscien ce.wiley.com/cochrane/clsysrev/articles/CD008225/frame.html.

Greenberg, M. T., Domitrovich, C., \& Bumbarger, B. (2001). The prevention of mental disorders in school-aged children: Current state of the field. Prevention \& Treatment, 4, 1-61. https://doi. org/10.1037/1522-3736.4.1.41a.

Hattie, J. (2009). Visible learning: A synthesis of over 800 meta-analyses relating to achievement. London: Routledge, Taylor \& Francis Group.

Höök, B., \& Cederblad, M. (2008). Prövning av CBCL för förskolebarn (ASEBA). [Consideration of CBCL for preschool children $(A S E B A)]$. Umeå: Umeå Universitet.

Jacobson, N. S., \& Truax, P. (1991). Clinical significance: A statistical approach to defining meaningful change in psychotherapy research. Journal of Consulting and Clinical Psychology, 59, 12-19. https://doi.org/10.1037/0022-006X.59.1.12.

Kaminski, J. W., Valle, L. A., Filene, J. H., \& Boyle, C. L. (2008). A meta-analytic review of components associated with parent training program effectiveness. Journal of Abnormal Child Psychology, 36, 567-589. https://doi.org/10.1007/s10802-007-9201-9.

Lakens, D. (2013). Calculating and reporting effect sizes to facilitate cumulative science: A practical primer for $t$-tests and ANOVAs. Frontiers in Psychology. https://doi.org/10.3389/fpsyg .2013.00863.

Lambert, M. J., \& Ogles, B. M. (2009). Using clinical significance in psychotherapy outcome research: The need for a common procedure and validity data. Psychotherapy Research, 19, 493-501. https://doi.org/10.1080/10503300902849483.

Larsson, B., \& Frisk, M. (1999). Social competence and emotional/ behaviour problems in 6-16 year-old Swedish school children. European Child \& Adolescent Psychiatry, 8, 24-33. https://doi. org/10.1007/s007870050080.

Luthar, S. S., \& Cicchetti, D. (2000). The construct of resilience: Implications for interventions and social policies. Development and Psychopathology, 12, 857-885. https://doi.org/10.1017/S0954 579400004156.

Mendez, L. R., Ogg, J., Loker, T., \& Fefer, S. (2013). Including parents in the continuum of school-based mental health services: A review of intervention program research from 1995 to 2010. Journal of Applied School Psychology, 29, 1-36. https://doi. org/10.1080/15377903.2012.725580. 
Moffitt, T. E. (2003). Life-course persistent and adolescence-limited antisocial behavior: A 10-year research review and a research agenda. In T. E. Lahey, T. E. Moffitt \& A. Caspi (Eds.), Causes of conduct disorder and juvenile delinquency (pp. 49-75). New York: Guilford Press.

Morris, S. B. (2008). Estimating effect sizes from pretest-posttestcontrol group designs. Organizational Research Methods, 11, 364-386. https://doi.org/10.1177/1094428106291059.

Olsson, M., Hansson, K., \& Söderlind, M. (2012). Teacher estimates of emotional and behavioral problems in students aged 6-16 years: A normative study of the Teacher Report Form (TRF). Umeå: Umeå Universitet.

Overall, J. E., Tonidandel, S., \& Starbuck, R. R. (2009). Last-observation-carried-forward (LOCF) and tests for difference in mean rates of change in controlled repeated measurements designs with dropouts. Social Science Research, 38, 492-503. https://doi. org/10.1016/j.ssresearch.2009.01.004.

Øvreeide, H., \& Hafstad, R. (1996). The Marte Meo method and developmental supportive dialogues. Haardervijk: Aarts Production.

Patterson, G. R., DeGarmo, D. S., \& Knutson, N. (2000). Hyperactive and antisocial behaviors: Comorbid or two points in the same process? Development and Psychopathology, 12, 91-106. https ://doi.org/10.1017/S0954579400001061.

Patterson, G. R., Reid, J. B., \& Dishion, T. J. (1992). Antisocial boys. Eugene: Castalia.

Paulus, F. W., Ohmann, S., \& Popow, C. (2016). Practitioner review: School-based interventions in child mental health. Journal of Child Psychology \& Psychiatry, 57, 1337-1359. https://doi. org/10.1111/jcpp.12584.

Petitt, B. (2016). System, context and psychotherapy: Towards a unified approach. North Charleston: Createspace Independent Publishing Platform

Reddy, L. A., Newman, E., De Thomas, C. A., \& Chun, V. (2009). Effectiveness of school-based prevention and intervention programs for children and adolescents with emotional disturbance: A meta-analysis. Journal of School Psychology, 47, 77-99. https ://doi.org/10.1016/j.jsp.2008.11.001.

Reid, J. B., \& Eddy, J. M. (2002). Preventive efforts during the elementary school years: The linking the interests of families and teachers project. In J. B. Reid, G. R. Patterson, J. Snyder, J. B. Reid, G. R. Patterson \& J. Snyder (Eds.), Antisocial behavior in children and adolescents: A developmental analysis and model for intervention (pp. 219-233). Washington, DC: American Psychological Association.

Rutter, M. (2000). Resilience reconsidered: Conceptual considerations, empirical findings, and policy implications. In J.P. Shonkoff \& S.J. Meisels (Eds.), Handbook of early childhood intervention (Vol. 2, pp. 651-682), Cambridge: Cambridge University Press.

Rutter, M. (2013). Annual research review: Resilience-clinical implications. Journal of Child Psychology and Psychiatry, 54, 474487. https://doi.org/10.1111/j.1469-7610.2012.02615.x.

Rutter, M., Moffitt, T. E., \& Caspi, A. (2006). Gene-environment interplay and psychopathology: Multiple varieties but real effects. Journal of Child Psychology and Psychiatry, 47, 226-261. https ://doi.org/10.1111/j.1469-7610.2005.01557.x.

Sameroff, A. J., \& Fiese, B. H. (2000). Transactional regulation: The developmental ecology of early intervention. New York: Cambridge University Press.

Sanchez, A. L., Cornacchio, D., Poznanski, B., Golik, A. M., Chou, T., \& Comer, J. S. (2018). Review: The effectiveness of schoolbased mental health services for elementary-aged children: A meta-analysis. Journal of the American Academy of Child \& Adolescent Psychiatry, 57, 153-165. https://doi.org/10.1016/j. jaac.2017.11.022.
Scott, S. (2002). Parent training programmes. In M. Rutter \& T. Taylor (Eds.), Child and adolescent psychiatry (pp. 949-967). Oxford: Blackwell Science.

Seikkula, J., Arnkil, T. E., \& Eriksson, E. (2003). Postmodern society and social networks: Open and anticipation dialogues in network meetings. Family Process, 42, 185-203. https://doi.org/10.111 1/j.1545-5300.2003.42201.x.

Sheridan, S. M., \& Moorman Kim, E. (Eds.). (2015). Foundational aspects of family school partnership research. New York: Springer International Publishing.

Snyder, J., Cramer, A., Afrank, J., \& Patterson, G. R. (2005). The contributions of ineffective discipline and parental hostile attributions of child misbehavior to the development of conduct problems at home and school. Developmental Psychology, 41, 30-41. https:// doi.org/10.1037/0012-1649.41.1.30.

Sroufe, L. A., Coffino, B., \& Carlson, E. A. (2010). Conceptualizing the role of early experience: Lessons from the Minnesota longitudinal study. Developmental Review, 30, 36-51. https://doi. org/10.1016/j.dr.2009.12.002.

Stewart-Brown, S. (2008). Improving parenting: The why and the how. Archives of Disease in Childhood, 93, 102-104. https://doi. org/10.1136/adc.2006.113522.

Stewart-Brown, S., \& Schrader-McMillan, A. (2011). Parenting for mental health: What does the evidence say we need to do? Report of Workpackage 2 of the DataPrev project. Health Promotion International, 26, i10-i28. https://doi.org/10.1093/heapro/dar056.

Stoltz, S., van Londen, M., Dekovic, M., de Castro, B. O., \& Prinzie, P. (2012). Effectiveness of individually delivered indicated school-based interventions on externalizing behavior. International Journal of Behavioral Development, 36, 381-388. https:// doi.org/10.1177/0165025412450525.

Swedish Statute Book 2010:800. (2010). Swedish school law. Stockholm: Department of Education.

Warren, J. S., Nelson, P. L., Mondragon, S. A., Baldwin, S. A., \& Burlingame, G. M. (2010). Youth psychotherapy change trajectories and outcomes in usual care: Community mental health versus managed care settings. Journal of Consulting and Clinical Psychology, 78, 144-155. https://doi.org/10.1037/a0018544.

Webster-Stratton, C., Reid, M. J., \& Beauchaine, T. (2011). Combining parent and child training for young children with ADHD. Journal of Clinical Child and Adolescent Psychology, 40, 191-203. https ://doi.org/10.1080/15374416.2011.546044.

Webster-Stratton, C., \& Taylor, T. (2001). Nipping early risk factors in the bud: Preventing substance abuse, delinquency, and violence in adolescence through interventions targeted at young children (0-8 years). Prevention Science, 2, 165-192. https://doi. org/10.1023/A:1011510923900.

Wilson, S. J., \& Lipsey, M. W. (2007). School-based interventions for aggressive and disruptive behavior. Update of a meta-analysis. American Journal of Preventive Medicine, 33, 130-143. https:// doi.org/10.1016/j.amepre.2007.04.011.

Wirtberg, I. (2014). Better health among Skara's children and adolescents. Local cross-sectoral public health. Skara kommun: Lunds Universitet.

Wirtberg, I., Petitt, B., \& Axberg, U. (2013). Marte Meo and coordination meetings: MAC_cooperation to support children's development. Lund: Palmkrons förlag.

Wolpert, M., Görzig, A., Deighton, J., Fugard, A. J. B., Newman, R., \& Ford, T. (2015). Comparison of indices of clinically meaningful change in child and adolescent mental health services: Difference scores, reliable change, crossing clinical thresholds and 'added value' - an exploration using parent rated scores on the SDQ. Child \& Adolescent Mental Health, 20, 94-101. https://doi. org/10.1111/camh.12080. 